Original Research Article

\title{
Knowledge, attitude and practice of generic medicines among doctors in a tertiary care teaching hospital of Tripura, India
}

\author{
Prithul Bhattacharjee*, Lakshman Das, Ranjib Ghosh, Uttam K. Das, Maitrayee Chakraborty
}

Department of Pharmacology, Tripura Medical College and Dr. B. R. Ambedkar Memorial Teaching Hospital, Agartala, Tripura, India

Received: 25 April 2017 Accepted: 29 April 2017

*Correspondence to: Dr. Prithul Bhattacharjee, Email: drprithulb@gmail.com

Copyright: (C) the author(s), publisher and licensee Medip Academy. This is an openaccess article distributed under the terms of the Creative Commons Attribution NonCommercial License, which permits unrestricted noncommercial use, distribution, and reproduction in any medium, provided the original work is properly cited.

\begin{abstract}
Background: The assessment of doctors' perceptions and understanding about generic medicines may help in recognizing possible barriers to greater generic medicine usage. The primary objective of this study was to explore the knowledge, attitude, and practice (KAP) of doctors toward generic medicines.

Methods: A questionnaire based cross-sectional study was carried out in a tertiary-care teaching hospital of Tripura. The questionnaire was designed to assess the KAP about generic medicines. The doctors working in this institute during the study period were included. All data were analysed using statistical software for epidemiology (EPI6). P $<0.05$ was considered statistically significant.

Results: $67.5 \%$ doctors agreed to the fact that generic medicines were intended to be interchangeable with a branded drug $(\mathrm{p}=0.0003)$. Among the doctors, $95 \%$ were aware that generic drug manufacturers need to conduct studies to show bioequivalence between the generic medicine and their branded counterparts ( $\mathrm{p}$ $<0.0001)$. Majority of the doctors $(82.5 \%)$ were of the view that generic medicines were as safe as that of branded drugs ( $\mathrm{p}<0.0001$ ). $97.5 \%$ of the doctors agreed that importance of generic medicines should be taught in early part of internship. $75 \%$ doctors did not think that switching a patient from a brand-name to generic drug may change the outcome of the therapy ( $p<0.0001) .92 .5 \%$ doctors said that they prescribe generic medicines $(\mathrm{p}<0.0001)$.

Conclusion: The study showed that the doctors were well aware of generic medicines and Jan Aushadhi scheme of Govt. of India. It was also observed that efficacy, safety and quality profile of the medicine were the most important factors considered by doctors when they prescribe drugs.
\end{abstract}

Keywords: Attitude, Generic medicine, Knowledge, Practice

\section{INTRODUCTION}

The rising health-care expenses remain a serious concern for the health-care system worldwide. As reported by the WHO, in many developing countries out-of-pocket expenses may go up to as high as $80 \%$ of total health-care expenditures. ${ }^{1}$ The cost incurred on medicine is one of the major concerning components of that expenditure. Hence, the need of the hour is to keep health-care costs nominal without hampering the access to quality health care. ${ }^{2}$ As we aim to cater high-quality health-care system to the masses with limited available resources, increased usage of generic medicines can improve affordability of the health care without compromising the quality. ${ }^{3}$ The prescription written by the doctors has a significant ramification on the usage of generic medicines, particularly in developing countries where patients or relatives leave no stone unturned to buy precisely what is prescribed. $^{4}$

However, doctors' viewpoint about generic medicines may pose a decisive hurdle to large-scale usage, culminating in increased health-care expenses. Physicians may favour branded medicines on various accounts. Many doctors may believe that generic medicines are not as effective and safe as their brand-name counterparts. ${ }^{5}$ 
Therefore, understanding doctors' perceptions and an understanding about generic medicines may help in recognizing possible barriers to greater generic medicine usage ${ }^{6}$ Hence, the primary objective of this study was to explore the knowledge, attitude, and practice (KAP) of doctors towards generic medicines.

\section{METHODS}

\section{Study site}

The study was carried out at Tripura Medical College and Dr. B.R. Ambedkar Memorial Teaching Hospital (TMC), a 560 bedded tertiary care teaching hospital located in the north-eastern region of India.

\section{Study design}

This was a questionnaire based cross-sectional study to assess the KAP of generic medicines among prescribers working in this hospital. The duration of the study was one month from $1^{\text {st }}$ November 2016 to 30th November 2016.

\section{Sample size}

The sample size was calculated using the formula 4PQ/L2, where $\mathrm{P}=$ positive factor/prevalence/proportion, $\mathrm{Q}=1-\mathrm{P}$, $\mathrm{L}=$ allowable error or precision or variability. The approximate sample size was 120 ..

\section{Inclusion criteria}

Doctors from all specialities working in the hospital during the study period were included after obtaining an informed consent.

\section{Exclusion criteria}

Those who were not willing to participate or did not return the questionnaire within the stipulated time were excluded.

\section{Study tools}

A KAP questionnaire containing 31 questions (12 questions pertaining to knowledge of generic medicines, 12 questions eliciting participants' attitude towards generic medicines and 7 questions related to practice of generic medicines) was designed using the precedence set by similar studies to obtain information regarding the demographics of the participants, knowledge regarding generic medicines, attitude towards generic medicines and practice of generic medicines, and the factors that influence the prescription of medicines. ${ }^{3,7,8}$

The questionnaire in relation to knowledge, attitude and practice are given in Table 2, Table 3 and Table 4 respectively. The doctors were requested to complete the questionnaire and return it within 01(one) day to Adverse drug reaction Monitoring Centre (AMC), TMC. Any clarification needed in understanding the questionnaire was provided.

\section{Data analysis}

The data was analysed by using statistical software for epidemiology (EPI6). P < 0.05 was considered statistically significant.

\section{RESULTS}

\section{Demographic Characteristics}

The demographic characteristics of the participants have been summarised in Table 1.

Table 1: Demographic details of the participants $(\mathrm{n}=120)$.

\begin{tabular}{|c|c|c|}
\hline Factors & & Number (\%) \\
\hline \multirow{2}{*}{ Gender } & Male & $90(75)$ \\
\hline & Female & $30(25)$ \\
\hline \multirow{5}{*}{ Age (years) } & $<30$ & $72(60)$ \\
\hline & $30-40$ & $27(22.5)$ \\
\hline & $41-50$ & $03(2.5)$ \\
\hline & $51-60$ & $00(0)$ \\
\hline & $>60$ & $18(15)$ \\
\hline \multirow{2}{*}{ Qualification } & Graduate & $7865)$ \\
\hline & Post graduate & $42(35)$ \\
\hline
\end{tabular}

\section{Response rate}

A total of 120 questionnaires were distributed among doctors and all of them responded i.e., response rate was $100 \%$.

\section{Knowledge about generic medicines}

$67.5 \%$ doctors agreed that generic medicines were intended to be interchangeable with a branded drug ( $\mathrm{p}$ $<0.001)$. Most of the doctors $(80 \%)$ were aware that generic medicines were only marketed after the expiry of the patent period of the innovator drug ( $\mathrm{p}<0.001)$.

92.5\% doctors had knowledge that composition, dose and indications of generic medicines were same as the branded counterparts ( $\mathrm{p}<0.001)$. Among the study participants $35 \%$ were aware that repetition of preclinical and clinical studies was not required for manufacturing generic medicines $(p=0.0018) .95 \%$ of the participants believed that generic medicines were an important tool to reduce the overall health care expenditure.

95\% doctors were aware that bioequivalence studies must be conducted by generic drug manufacturers. Most of the doctors $(90 \%)$ were aware that drugs with generic names should be prescribed by every physician as stated in the Indian Medical Council Act (Professional conduct, Etiquette and Ethics) Regulations, 2002 (p <0.001). All the 
participants were aware of the Jan Aushadhi Scheme of Govt. of India whose purpose was to set up generic drug stores around the country. $72.5 \%$ doctors believed that generic medicines were equally efficacious as their branded counterparts $(\mathrm{p}<0.001)$. All the participants had information regarding presence of a generic medicines store in this hospital. $32.5 \%$ doctors believed that the quality of brand name medicines was better than that of generic medicines $(\mathrm{p}<0.001)$. Only $15 \%$ participants believed that brand name medicines produced lesser side effects than generic medicines ( $p<0.001)$. Knowledge related questionnaire and their responses have been summarised in Table 2.

Table 2: Knowledge related questions and frequency of responses.

\begin{tabular}{|c|c|c|c|c|}
\hline S. no. & Questions & Yes $(\%)$ & No $(\%)$ & P value \\
\hline 1. & Generic medicines intended to be interchangeable with a branded drug & $81(67.5 \%)$ & $39(32.5 \%)$ & 0.0003 \\
\hline 2. & $\begin{array}{l}\text { Generic medicines only marketed after the expiry of patent period of } \\
\text { innovator drug }\end{array}$ & $24(20 \%)$ & $96(80 \%)$ & 0.0001 \\
\hline 3. & $\begin{array}{l}\text { Composition, dose and indications of generic medicine are same as } \\
\text { branded medicine }\end{array}$ & $111(92.5 \%)$ & $09(7.5 \%)$ & 0.0001 \\
\hline 4. & $\begin{array}{l}\text { Preclinical and clinical studies should be repeated for manufacture of } \\
\text { generic medicine }\end{array}$ & $78(65 \%)$ & $42(35 \%)$ & 0.0018 \\
\hline 5. & $\begin{array}{l}\text { To reduce overall health expenditure generic medicines are important } \\
\text { tool }\end{array}$ & $114(95 \%)$ & $06(5 \%)$ & 0.0001 \\
\hline 6. & $\begin{array}{l}\text { Generic medicines manufacturers need to conduct bioequivalence } \\
\text { studies }\end{array}$ & $114(95 \%)$ & $06(5 \%)$ & 0.0001 \\
\hline 7. & $\begin{array}{l}\text { Indian medical council act (Professional conduct, etiquette and ethics) } \\
\text { regulations, } 2002 \text { states that every physician should, as far as possible, } \\
\text { prescribe drugs with generic medicines }\end{array}$ & $108(90 \%)$ & $12(10 \%)$ & 0.0001 \\
\hline 8. & $\begin{array}{l}\text { Are you aware of the scheme of Govt. of India called 'Jan Aushadhi' } \\
\text { whose purpose is to set up generic drug stores around the country }\end{array}$ & $120(100 \%)$ & 0 & \\
\hline 9. & Generic medicines are equally efficacious as branded drugs & $87(72.5 \%)$ & $33(27.5 \%)$ & 0.0001 \\
\hline 10. & Are you aware that generic drug store is available in our hospital & $120(100 \%)$ & 0 & \\
\hline 11. & Brand name medicines are of good quality than generic medicines & $39(32.5 \%)$ & $81(67.5 \%)$ & 0.0003 \\
\hline 12. & $\begin{array}{l}\text { Brand name medicines produce lesser side effects than generic } \\
\text { medicines }\end{array}$ & $18(15 \%)$ & $102(85 \%)$ & 0.0001 \\
\hline
\end{tabular}

\section{Attitude towards generic medicines}

Majority of the doctors $(82.5 \%)$ were of the view that generic medicines were as safe as that of branded drugs ( $p$ $<0.001) .90 \%$ of the doctors did not agree that generic medicines used to take longer time to act in the body ( $\mathrm{p}$ $<0.001)$. $60 \%$ of the participants denied that generic medicines were often made in substandard facilities as compared to brand name drugs $(\mathrm{p}=0.0305)$. Another $87.5 \%$ of the doctors did not agree that generic medicines were cheaper because they were inferior to brand name drugs. 95\% of the doctors agreed that there should be a training programme to increase the awareness regarding generic medicines among doctors and patients. All the doctors responded that there should be a generic medicine store in every hospital and also believed that patient should have the liberty to choose generics over branded drugs. 55\% of the doctors had a view that generics of only reputed companies were safe $(p=0.2709)$. 90\% of the doctors disagreed that incentives should be paid for prescribing generic medicines ( $\mathrm{p}<0.001$ ). Only $2.5 \%$ of the doctors were of the view that generic medicines were meant only for the poor. $97.5 \%$ of the doctors agreed that importance of generics should be taught in early part of internship.
$92.5 \%$ of the participants were of the view that quality testing of generic medicines should be made more vigorous ( $\mathrm{p}<0.001$ ). Attitude related questionnaire and their responses have been summarised in Table 3 .

\section{Practice about generic medicines}

92.5\% of the doctors said that they prescribed generic medicines ( $\mathrm{p}<0.001$ ). $72.5 \%$ of the participants did not read any article on comparison of safety and efficacy of generic versus brand name medicines ( $p<0.001)$. A majority $(75 \%)$ of the doctors did not think that switching a patient from a brand name to generic medicines might change the outcome of therapy. Most of the doctors $(82.5 \%)$ said that medical representatives did not influence their prescription. Another $82.5 \%$ of the doctors were not comfortable if pharmacists changed branded drugs prescribed by them ( $p<0.001)$. 25\% of the doctors prescribed branded drugs because their names were easy to memorize ( $\mathrm{p}<0.001$ ). $62.5 \%$ of the doctors said that the demand of the patient did not influence their prescription $(\mathrm{p}=0.0081)$. Practice related questionnaire and their responses are summarised in Table 4 and Table 5. 
Table 3: Attitude related questions and frequency of responses.

\begin{tabular}{|lllll|}
\hline S. no. & Questions & Yes (\%) & No (\%) & P value \\
\hline 1. & Generics are not safe as branded drugs & $21(17.5 \%)$ & $99(82.5 \%)$ & 0.0001 \\
\hline 2. & Generics take longer time to act in the body & $12(10 \%)$ & $108(90 \%)$ & 0.0001 \\
\hline 3. & $\begin{array}{l}\text { Generics are often made in substandard facilities as compared to } \\
\text { brand name drugs }\end{array}$ & $48(40 \%)$ & $72(60 \%)$ & 0.0305 \\
\hline 4. & $\begin{array}{l}\text { Generic medicines are cheaper because they are inferior to brand } \\
\text { name drugs }\end{array}$ & $15(12.5 \%)$ & $105(87.5 \%)$ & 0.0001 \\
\hline 5. & $\begin{array}{l}\text { There should be a training programme to increase the awareness } \\
\text { regarding generic medicines among doctors and patients }\end{array}$ & $114(95 \%)$ & $06(5 \%)$ & 0.0001 \\
\hline 6. & There should be a generic medicine store in every hospital & $120(100 \%)$ & 0 & \\
\hline 7. & $\begin{array}{l}\text { Patient should have the liberty to choose generics over branded } \\
\text { drugs }\end{array}$ & $120(100 \%)$ & 0 & \\
\hline 8. & Generics of only reputed companies are safe & $66(55 \%)$ & $54(45 \%)$ & 0.2709 \\
\hline 9. & Incentives should be paid to doctors for prescribing generics & $12(10 \%)$ & $108(90 \%)$ & 0.0001 \\
\hline 10. & Generics are meant only for poor & $03(2.5 \%)$ & $117(97.5 \%)$ & 0.0001 \\
\hline 11. & Importance of generics should be taught in early part of internship & $117(97.5 \%)$ & $03(2.5 \%)$ & 0.0001 \\
\hline 12 & Quality testing of generics should be made more vigorous & $111(92.5 \%)$ & $09(7.5 \%)$ & 0.0001 \\
\hline
\end{tabular}

Table 4: Practice related questions and frequency of responses.

\begin{tabular}{|lllll|}
\hline S. no. & Questions & Yes (\%) & No (\%) & P value \\
\hline 1. & Do you prescribe generic medicines & $111(92.5 \%)$ & $09(7.5 \%)$ & 0.0001 \\
\hline 2. & $\begin{array}{l}\text { Have you any time read any article on comparison of safety and efficacy } \\
\text { of generic vs brand name medicines }\end{array}$ & $33(27.5 \%)$ & $87(72.5 \%)$ & 0.0001 \\
\hline 3. & $\begin{array}{l}\text { Switching a patient from a brand name to generics may change the } \\
\text { outcome of therapy }\end{array}$ & $30(25 \%)$ & $90(75 \%)$ & 0.0001 \\
\hline 4. & Do medical representatives influence your prescription & $21(17.5 \%)$ & $99(82.5 \%)$ & 0.0001 \\
\hline 5. & $\begin{array}{l}\text { Are you comfortable if pharmacists change branded drugs prescribed by } \\
\text { you }\end{array}$ & $21(17.5 \%)$ & $99(82.5 \%)$ & 0.0001 \\
\hline 6. & You prescribe branded drugs because their names are easy to memorize & $30(25 \%)$ & $90(75 \%)$ & 0.0001 \\
\hline 7. & Patients demands influence your prescription & $45(37.5 \%)$ & $75(62.5 \%)$ & 0.0081 \\
\hline
\end{tabular}

Table 5: The factors taken into consideration while prescribing a medicine to the patient.

\begin{tabular}{|ll|}
\hline Factors & Frequency (\%) \\
\hline Availability of drugs in pharmacies & $114(95 \%)$ \\
\hline Price of medicine & $114(95 \%)$ \\
\hline Efficacy and safety profile of drugs & $117(97.5 \%)$ \\
\hline Severity of illness & $111(92.5 \%)$ \\
\hline Economic profile of the patient & $117(97.5 \%)$ \\
\hline $\begin{array}{l}\text { Nature of hospital i.e. } \\
\text { private/government }\end{array}$ & $42(35 \%)$ \\
\hline $\begin{array}{l}\text { Lucrative gifts offered by } \\
\text { pharmaceutical companies }\end{array}$ & $6(5 \%)$ \\
\hline $\begin{array}{l}\text { Pressure from patients to prescribe } \\
\text { low cost medicines }\end{array}$ & $42(35 \%)$ \\
\hline
\end{tabular}

\section{DISCUSSION}

In the present study, good percentage of doctors have considerable knowledge about generic medicines and they have positive attitude about the safety, efficacy and quality of generic medicines. Most of the doctors used to prescribe generic medicines. These findings are similar to that of Gupta SK et al. ${ }^{7}$ Majority of the participants have knowledge that generic medicines are intended to be interchangeable with a branded drug which is in accordance with finding of Davit BM et al. ${ }^{9}$

In an earlier study, it has been seen that generic medicines function equivalently to their innovator counterparts. ${ }^{10} \mathrm{In}$ this study, $95 \%$ of the participants are aware that generic drug manufacturers need to conduct bioequivalence studies which is contrary to the finding $(63.2 \%)$ of Badwaik RT et al. ${ }^{8}$ Significantly, high numbers of participants agree that to reduce overall health expenditure generic medicines are an important tool. The cost of generic medicines has been found to be up to $91 \%$ less than that of the innovator medicine in India. ${ }^{11}$ All participants are aware of Jan Aushadhi scheme of Govt. of India whose purpose is to set up generic drug stores around the country which is contrary to the finding of Badwaik RT et al. ${ }^{8}$ Most of the participants believe that generic medicines are as safe as branded drug which is similar to the finding of Gupta SK et al. ${ }^{7}$ Only few participants believe that generic medicines take longer time to act. Surprisingly $40 \%$ of the 
participants are of the view that generics are often manufactured in substandard facilities.

Most of the participants believe that although generic medicines are cheaper, they are not inferior to branded drugs. All the participants have a view that every hospital should have a generic medicine store and patient should have the liberty to choose generic medicines over branded drugs. Interestingly most of participants are of the view that incentives should not be paid to doctors for prescribing generic medicines and there should be a training programme among doctors and patients to increase the awareness regarding generic medicines. Also, most of the participants believe that in early part of internship importance of generic medicines should be taught. In this study majority believe that quality testing of generic medicines should be made more vigorous which is similar to the finding of another study. ${ }^{8}$

In our study, we have found that most of the doctors prescribe generic medicines and their prescriptions are not influenced by medical representatives. A major chunk of participants believe that they prescribe branded drugs because their names are easy to memorize which is similar to the finding of another study. ${ }^{8}$ In the present study, we have found that prescribing habit of the doctors is not influenced by patient's demand which is contrary to the finding of Jamshed SQ et al. ${ }^{1}$ Most of the participants think that switching a patient from a brand name drug to generic drug does not change the outcome of the therapy which is similar to the finding of another study. ${ }^{7}$

Small sample size and less duration are the major limitations of this study. So, the findings of this study cannot be generalized. We have only studied the doctors' perception and understanding regarding generic medicines. It would be appropriate to analyse the perception and understanding of other health care professionals as well as patients.

\section{CONCLUSION}

The present study showed that the doctors have well information regarding generic medicines and Jan Aushadhi scheme of Govt. of India. There should be various training programmes to increase the awareness regarding generic medicines among health care professionals and patients. The endeavour should be to educate the doctors early in their career about the advantages of prescribing generic medicines. ${ }^{12,13}$ In this study, it is observed that efficacy, safety and quality profile of the medicine are the most important factors considered by doctors when they prescribe drugs. Further work is needed on how interventions for medical professionals and for the public can reduce negative attitudes about efficacy, safety and side effects, in order to increase the acceptability of generic medicines.

\section{ACKNOWLEDGMENTS}

Authors would like to thank the doctors who participated in this study by filling up the questionnaire. The authors are also grateful to the Principal, Tripura Medical College and Dr. B. R. Ambedkar Memorial Teaching Hospital, Agartala, Tripura for providing the necessary facilities to carry out this study.

\section{Funding: No funding sources}

Conflict of interest: None declared

Ethical approval: The study was approved by the Institutional Ethics Committee

\section{REFERENCES}

1. Jamshed SQ, Hassali MA, Ibrahim MI, Babar ZU. Knowledge attitude and perception of dispensing doctors regarding generic medicines in Karachi, Pakistan: a qualitative study. J Pak Med Assoc. 2011;61:80-3.

2. Bakthavathsalam G. Generic medicines: cost effective alternative to branded drug, Health Administrator. 2006;19:16-9.

3. Jamshed SQ, Ibrahim MIM, Hassali MA, Masood I, Low BY, Shafie AA, et al. Perception and attitude of general practitioners regarding generic medicines in Karachi, Pakistan: a questionnaire based study. Southern Med Rev. 2012;5(1):22-30.

4. Hassali MA, Shafie AA, Jamshed S, Ibrahim MI, Awaisu A. Consumers' views on generic medicines: a review of the literature. Int J Pharm Pract. 2009; 17:7988.

5. King DR, Kanavos P. Encouraging the use of generic medicines: implications for transition economies. Croat Med J. 2002;43:462-9.

6. Shrank WH, Cox ER, Fischer MA, Mehta J, Choudhry NK. Patients' perceptions of generic medications. Health Aff. (Millwood). 2009;28:546-56.

7. Gupta SK, Nayak RP, Vidyarthi SK. A study on the knowledge, attitude and practice of generic medicines among the doctors in a tertiary care teaching hospital in South India. National Journal of Physiology, Pharm Pharmacol. 2015;5(1):39-44.

8. Badwaik RT, Chopade SS, Mahajan HM, Honrao R. Prescribers Views on Generic Medicines: A Study on Knowledge, Attitude and Practice. J Cont Med A Dent. 2015;3(2):27-32.

9. Davit BM, Nwakama PE, Buehler GJ, Conner DP, Haidar SH, Patel DT et al. Comparing generic and innovator drugs: a review of 12 years of bioequivalence data from the United States Food and Drug Administration. Ann pharm. 2009;43:1583-97.

10. Dunne S, Shannon B, Dunne C, Cullen W. A review of the differences and similarities between generic medicines and their originator counterparts, including economic benefits associated with uses of generic medicines, using Ireland as a case study. BMC Pharmacol Toxicol. 2013;14:1. 
11. Lopes Gde L. Cost comparison and economic implications of commonly used originator and generic chemotherapy drugs in India. Ann Oncol. 2013;24(5):13-6.

12. Sharrad AK, Hassali MA, Shafie AA. Generic medicines: perception of physicians in Basrah, Iraq. AMJ. 2009;1(8):58-64.
13. Alghasham AA. Generic drug prescribing in central Saudi Arabia: Perceptions and attitudes of physicians. Ann Saudi Med. 2009;29:24-9.

Cite this article as: Bhattacharjee $\mathrm{P}$, Das L, Ghosh R, Das UK, Chakraborty M. Knowledge, attitude and practice of generic medicines among doctors in a tertiary care teaching hospital of Tripura, India. Int $\mathbf{J}$ Basic Clin Pharmacol 2017;6:1287-92. 